\title{
MANAGING THE FLOW OF INFORMATION ON AN ENTERPRISE SOCIAL NETWORK
}

\author{
Michael Stul, mstulphd@gmail.com \\ Conducive Corporation, Chicago, Illinois, USA
}

\begin{abstract}
Using an Enterprise social network called Yammer as an example the article examines the practices for managing the flow of information on an Enterprise social network. Enterprise social networks are fairly common in today's workplace. They serve many purposes. Some social networks help promote a collaborative work environment. They support employee interaction within a group. These networks have proven effective as a way to improve communication between project team members and between company employees in general. Enterprise social networks, however, can also offer a platform for promoting a broad cultural change in a company. When it comes to influencing human behavior, their role is paramount. The role of an Enterprise social network in promoting a culture change in a company, however, is far less explored than its role as a communication means. In the US industry, a specific discipline studies and employs the practices of influencing employee behavior and motivations. This discipline is called Organizational Change Management (OCM). OCM is specifically interested in studying new channels for relaying information about a change to employees. How do you best manage the flow of information in a corporate social network to achieve maximum efficiency? What is the best communication channel to influence employee behaviors to achieve and sustain company goals? This article examines the practices of channeling information to company employees and from employees to Senior Leadership using an Enterprise social network.

Target audiences for this article include Senior Management, members of the Project Management Organizations (PMO), Organizational Change Management Organizations (OCMO), training teams, and organizational development consultants.

Keywords: social networks, social media, Yammer, Facebook, Instagram, Enterprise, information, USA, Enterprise, Organizational Change Management, OCM, Social SafeGuard.
\end{abstract}

\section{Overview of the Current Social Networking Landscape}

Employing Enterprise social networks as a venue for employee communications is a relatively new practice in the United States industry. The fact that the use of social networks is still not a common practice in the US industry is somewhat unexplainable. First, the need for a social network used exclusively in the workplace has been recognized almost a decade ago. In 2008, Microsoft has launched Yammer. Yammer has been positioned as a pioneer product in the Enterprise social network field. Second, social networks are so common it is now hard to imagine our lives without them. The birth of social networking has occurred as early as in the late seventies. In 1979, a user network called UseNet allowed users to communicate through a virtual newsletter. In the eighties, early forms of social networking, Internet relay chats (IRCs) have emerged and continued to be popular well into the nineties. The first social media site that resembled the current social media networks, called Six Degrees, was created in 1997. It enabled users to upload a profile and make friends with other users. In 1999, the first blogger sites have started. Their popularity has exploded in the early 2000. In the modern social communications landscape, it is almost impossible to find a field which does not have an established group of followers. And social networking is no longer limited to one continent. Established in 2006, Facebook and Twitter became available to users throughout the world. And then Tumblr, Spotify, Foursquare, and Pinterest began filling specific social networking niches.

With all this variety, it is a small miracle that, ten years later, Enterprise social networks are not a common place in every company across the world. It is not surprising, however, that we have observed a popularity growth of Enterprise social networks in the United States industry in the last few years. Something ought to be said about the reasons this growth is happening now and not ten years earlier.

First, a broad acceptance of Enterprise professional social networks in the industry has occurred, at least, in part, due to demographic changes in the modern workforce. Starting in the late teens, 
the Millennials began joining the workforce. For this employee group, communicating and collaborating via social networks is such a common experience that it was natural to bring this experience along when they left high school and joined the workforce. The culture of collaboration and communication via a social network is already in place for the Millennials. To encourage the use of Enterprise social networks, it was just a matter of giving these folks a specialized tool for collaboration. Not only was there no need to change their culture for them to start using the tool, there was no need to train the Millennials on the new functionality, either, irrespective of which tool their employer uses - so intuitive it was for them.

Second, Enterprise social networks follow in the footsteps of Tumblr, Spotify, VK and other specialty networks. This software is a niche network. As such, it serves certain stakeholder groups and the needs of certain user populations. Facebook has blazed the trail by standardizing the practice of creating interest groups. An interest group is a compartmentalized group that exists somewhat autonomously in the space of a Facebook. It does follow the guidelines established for all Facebook users. It assumes, however, that a user can join a specific user community within Facebook while not becoming a member of the other gazillion groups within the network. Facebook, however, serves a specific purpose: it is a social, not professional network. Someone's social life may be quite different from, or even in conflict with, their professional life. For that reason, many companies view Facebook as a distraction rather than a tool conducive to productive work. With this notion in place, professional networks, such as LinkedIn have found their way into our professional lives. LinkedIn has become so popular that having a profile on LinkedIn is now a must for many (most?) professionals across the globe. It is ironic, but our familiarity with a new place of potential employment and our future coworkers starts with reviewing their LinkedIn profile. Yet LinkedIn is not a true Enterprise social network, as it is not a collaboration tool. Once we become a member of a team, the needs for collaboration and information exchange with other team members requires a dedicated platform that LinkedIn does not provide.

Third, social networks have expanded into employing more than one type of media for communications purposes. Starting in the 2000, social media sites, such as MySpace, PhotoBucket, Instagram, and Flickr facilitated online photo sharing. In 2005, YouTube came out creating an entirely new way for people to communicate and share information by posting videos and commenting on other people's experiences documented in the videos. In short, social networks have started providing a framework and platforms for sharing user experience via a variety of channels (video, photo, and text messaging/blogs). A professional Enterprise social network is a niche platform that combines the core capabilities of Facebook (creating and running a group, creating posts, "liking" someone's posts), PhotoBucket or Instagram (posting pictures), and YouTube (posting videos and comments). A professional Enterprise social network fits nicely into the paradigm of a common user who is familiar with all information channels through the use of other social networks. For today's users, the use of an Enterprise network for collaboration and group communications is natural and intuitive. It also serves other purposes, such as being a source of information and learning experience. "Our data suggests that the combination of theoretically informed pedagogical design paired with the use of lightweight social media technology can provide students with opportunities to engage in learning processes associated with a community of learners approach to instruction without requiring unsustainable management practices from instructors" [1].

\section{What is in it for Organizational Change Management?}

In the United States industry, the formal communications space is actively and professionally managed. Many companies have either Organizational Change Management Organizations or hire professional communications and change specialists to manage corporate communications and changes. What is Organizational Change Management?

In the United States industry, Organizational Change Management Organization (OCMO) is an organization that employs communications for the purposes of supporting organizational changes. Organizational Change Management (OCM) is a discipline that is most commonly defined as a coordinated practice or structured approach to ensure the effective transition of individuals, teams and organizations from the current state to a desired future state. It ensures a solution that is applied to support the new state is embraced, adopted, and used proficiently. PROSCI, world's leading organization that develops change management methodologies and tools defines Organizational Change Management as a "discipline that guides how we prepare, equip and support individuals to successfully adopt change in order to drive organizational success and outcomes" [2]. 


\section{Управление в социально-экономических системах}

In other words, Organizational Change Management is a discipline that allows for steering employee behavior in the desired direction that ensures the company in general reaches its goals. OCM employs the current research in human behavior to ensure efficiency of its methods. These methods include a broad use of social and professional (including Enterprise) media, creating and maintaining change networks to support employee activities during and after projects, and active engagement of change enthusiasts (also called Change Champions). Other OCM methods include using targeted messaging, dedicated SharePoint sites, presentations, campaigns, posters, broadcasts, employee training, and other engagements. These methods are very efficient in ensuring employees are aware of the upcoming changes and are adequately prepared for them [3]. So, what is in Enterprise social networks for Organizational Change Management?

Organizational Change Management has a specific interest in the internal Enterprise communications domain. Using Enterprise social networks has proven very effective in accomplishing OCM goals. An Organizational Change Management Organization (OCMO) has multiple roles in ensuring employee readiness for a change. These roles include governance, oversight, support, and performance (sometimes also called production). These roles are often summarized in an abbreviation - GOSP. OCMO's Governance role entails creating processes, procedures, and guidelines for facilitating a social change in an Enterprise environment. OCMO's Oversight role entails collecting and analyzing data relative to the use of these policies, procedures, and guidelines to ensure the current behavioral and cultural practices are aligned with the approved practices set forth by the company. OCMO's Support role entails planning and executing corrective actions that help bridge the gaps between the current behavioral and cultural practices and the desired employee behaviors and Enterprise culture. Finally, OCMO's performance or production role is synonymous with staff augmentation: providing trained professional OCM resources to the company for helping execute and sustain a change. The use of Enterprise social networks has proven effective in all aspects of OCMO's GOSP. Enterprise social networks help establish, promote, sustain, and change/improve Enterprise culture and employee behaviors. For that reason, OCMO is an avid engager and supporter of Enterprise social networks in the US industry.

\section{Enterprise Social Networks}

The world of Enterprise social networks is fairly diverse. In a matter of minutes, anyone interested in learning about Enterprise social networks can come up with the list that includes Yammer, Tibbr, Jive, SocialCast, Convo, Kaltura, Chatter, Zyncro, SocialText, and Connections, to name just a few key players. As a rule, an Enterprise social network is marketed by a key Enterprise player. For example, Yammer is a Microsoft product (a company that started Yammer has been purchased by Microsoft in 2012). Salesforce came up with Chatter. Tibbr is a product by TIBCO. VMware developed SocialCast. Connections is an IBM product. The list is extensive. Each product, however, serves its purpose and has its own niche in the Enterprise communications culture. Let's focus on commonalities, however. The common core of each Enterprise social network product is the ability to create employee communities. For example, Chatter allows for creating a separate community for sales, clients and employees all in one centralized location. Social networks provide a centralized workplace and communication center for employees. Research show that employee communications are key to employee productivity. For example, here is what researchers conclude about employee communities that use Yammer. "Companies that use Yammer have employees that feel more engaged, they feel more connected to their coworkers, they feel more connected to the company's mission" [4]. There are many ways an Enterprise social network can support employee communications. Enterprise social network users can create public or private groups, share documents and manage common tasks and projects. For example, SocialCast supports employee collaboration when working on a project together. Most Enterprise social networks are built around collaboration focusing on a common task for a group. For example, Convo allows for discussing a micro-content in a thread. As you can see, many Enterprise social networks provide a platform for group collaborative efforts around common tasks or project works. This is expected of an Enterprise, work-related network. In a sense, each platform provides an instrument for communicating and sharing work-related information. Interestingly enough, however, in the US industry, companies nowadays have plenty of other platforms and tools that are designed to support collaboration around projects and daily tasks. To name just a few, SharePoint, OneDrive, Skype for Business, all part of the 2016 Office 365 for Business release. What may have been missing in most of Enterprise social networks is the ability to 
promote broad cultural changes, ensure information flow across various groups, and support a dialog between various levels of Enterprise hierarchies. This is the reason that sets one of the social networks apart from all other networks. I am referring to Microsoft's Yammer. Yammer is not the best when it comes to supporting project works. Yet today it is, perhaps, the most capable platform for supporting culture changes in a company.

\section{Yammer is a Potent Tool Used by Organizational Change Management Professionals}

For the purposes of this analysis we have selected a platform that is the most indicative of the Enterprise-wide information sharing process. This platform is called Yammer. Today, Microsoft's Yammer is a preferred platform in a company that is interested in promoting a cultural change among its employees. There are several reasons.

First, Yammer is, perhaps, the only tool whose User Interface is similar to Facebook, with status updates, picture-posting, praise, and follow capabilities. It is those capabilities that draw Organizational Change Management's attention to Yammer. Why has this happened?

In the United States industry, Organizational Change Management Organizations (OCMO) are charged with promoting innovative changes by maximizing adoption of a change among employees and eliminating employee resistance to change. From that standpoint, OCMO prefers using the existing venues as channels for communicating a change. For example, in a company with the 'top down' culture, an effort to rely on an employee network to promote a change 'from the bottom up' will likely fail. It is all a matter of learning about how information is flowing from its source to the intended audience and employing these information flows to a company's advantage. The familiar User Interface that Yammer employs gives it a big advantage over other Enterprise social networks. Employees are more likely to use a platform as a reliable information source if they are not distracted or discouraged by a complicated and unfamiliar interface and controls. A near-zero need to spend time on the training of employees on the communications channel alone is a part of OCMO's communications approach to managing information flow in a company. Everybody who has ever used Facebook (and it's near impossible to find anyone in the US who has not) will instantly adopt Yammer and start using it. No training on the functionality is needed. Naturally, Yammer which has a User Interface that is familiar to most of employees is likely to be a good information channel.

Second, as a discipline, Organizational Change Management manages human behaviors. Human behaviors are influenced and driven by emotions, attitudes, beliefs, feelings, habits and so on. By managing these emotional and spiritual components as behavioral motivators, OCMO efficiently manages employee behaviors that are both conducive to adopting a change and prevent rejection of a change. An Organizational Change Manager is very interested in systematically collecting and analyzing data about human emotions, both positive and negative, and the sources of emotion-related information. Yammer is the only social network that supports reading human emotions. When using Yammer, employees create posts. These posts express their feelings. Employee feelings can now be systematically analyzed using Yammer functionality called Crane. This functionality offers an insight into emotional trends demonstrated by employee groups within a company. The palette of emotions recognized by Yammer includes excitement, confusion and another 78 distinct emotions and feelings. Crane is capable of proving an analyst with a graph that shows how emotions in an employee group change over time. Yammer accomplishes this by recognizing the topics or words most often associated with these feelings. Employers nowadays employ multiple ways to obtain employee feedback on various events occurring in the company. Obtaining and analyzing human emotions is a unique feedback that provides Organizational Change Managers with an equally unique opportunity to develop a communications and training approach for driving employee behaviors in a desired direction. A continuous and systematic review of Yammer / Crane graphs over a period of time can also show whether that approach has successfully reached its behavioral target.

Third, Organizational Change Managers frequently employ change networks as an important channel to promote a change. Yammer content may become a powerful means of persuasion to change employee attitude and behaviors. "Computing technologies can take on functional roles as was stated in the introduction section and these roles define the persuasion context with the ultimate result being to change one's attitudes and behaviors or lead to compliance" [5]. Per Pietarinen, "Communication is a powerful tool when it is used right. Internal communication makes people: 1) understand why they 


\section{Управление в социально-экономических системах}

belong to work community, 2) work for the community and to other people since they understand mutual goals and enjoy their work, 3) do more and better quality because they are motivated, and 4) change their attitudes and opinions" [6].

Finally, Organizational Change Managers often create an employ change networks as a means to promote and support a chance. A change network is a group of employees who are designated as change champions. Change champions help promote a change in an organization. They help train other employees impacted by the change. They also help to disseminate information and relay employee feedback to the appropriate Organizational Change Managers. Typically, change champions are recruited among the most influential employees. Frequently, these influential employees are informal leaders. Sometimes, identifying and recruiting these influential informal leaders is a challenge for an Organizational Change Manager. On the one hand, Yammer can track emotions from a particular employee group, not individual employees. Yammer graphs of dominant emotions do not assign emotional readiness to individuals. On the other hand, Yammer is capable of highlighting influential employees who can sway the sentiment that other employees express. Yammer is an important tool for identifying these influential informal leaders in an organization. As David Sacks, Founder and CEO of Yammer, put it, "Yammer creates a private and secure enterprise social network - a social network just for the employees of a company... It helps expose who in the company has hidden expertise, who is contributing the most and who other people go to for answers" [7].

\section{Managing the Flow of Information in Yammer}

This section addresses the practices companies may employ to manage the flow of information on an Enterprise social network. There are many ways to utilize an Enterprise social network in a company. This article explores the practices for managing the flow of information for the purposes of communicating information about a culture change in a company. The practices that are reviewed in the article are discussed in connection with the functionality of the appropriate software programs and the staffing practices of Enterprise Organizational Change Management teams.

Please note that this article is not judging any current information flow management practices. It does not judge the way Yammer has been used in any particular Enterprise. A discussion of whether a company that is actively managing the flow of information in Yammer is behaving ethically by limiting access to information for some employees is out of scope for this article. The reason for not discussing the ethical aspect of information management is that evaluating these practices is a matter of perspective. One may choose to look at these practices as providing access to information for employees; others may choose to call these practices conducive to providing employees with broader access to information. In this article, Yammer is evaluated strictly as an additional venue for delivering information to company employees.

In the US, companies have been releasing Yammer to employees for a few years now. A quick Internet search reveals a substantial number of articles summarizing the guidelines for using Yammer. These articles are a good source for learning about the Yammer etiquette. Not every company, however, has been using Yammer for the purposes of facilitating a cultural change. In this article we are examining the practices of using Yammer from an Organizational Change Management perspective. Organizational Change Management is focusing on the most efficient ways to relay information to employees and from employees to Senior Leadership. "The purpose of communication is to maintain, empower and develop the work community, but also to educate individuals of the community through two-way interaction" [8].

The efficiency of an Enterprise social network depends on how well that network can manage the flow of information to stakeholders. What are the current practices for managing information flow in Yammer to facilitate a culture change in a company?

This article explores the following four of these practices:

- Employing a managed approach to using Yammer among company employees;

- Employing Yammer as a channel for managed communications;

- Actively governing, monitoring, and managing the content of employee communications in Yammer;

- Analyzing and acting on information obtained from employee communications in Yammer. 
This article does not reflect these practices with respect to any specific company. Rather, it discusses a generalized approach to how information flow management may be executed to support Enterprise communications objectives.

\section{Employing a Managed Approach to Using Yammer Among Company Employees}

A managed approach to using Yammer among company employees entails applying restrictions on the key social network activities, such as creating groups and facilitating employee activities within a group. At first glance, this approach looks counterintuitive in a social network environment. A social network entails openness and empowerment of its members. On Facebook, any Facebook user can create a social group, just as any Facebook user may request to become a member in a social group. These principles seem fundamental to a social network, as they empower social network users to make decisions and create and disseminate content. As long as those content and group activities comply with a social network's policies and do not violate a user agreement, the Administration of a social network does not interfere with a group's activities. As an Enterprise social network, Yammer may be governed by different rules. As part of a managed approach to social networking, companies can choose to restrict employee rights to create a group or join a group. They can also manage a content created and communicated by a group. In a company that employs the managed approach to social networking, a designated System Administrator may be selected to create and manage Yammer social network groups. Unlike Facebook, an Enterprise System Administrator is an employee that is not a member of a specific group. When managing a social group, a System Administrator systematically emails an invitation to an employee to join a group. The function to send an invitation to Yammer to an employee could be programmed into Yammer. For example, when a new employee joins the company's specific department or changes his/her role, s/he automatically receives an invitation to join a designated Yammer group. To reiterate: this may not be an Enterprise social group of his or her choosing. Rather, that is a group to which that employee belongs as designated by the System Administrator who follows company policies. In a managed approach to social networking, employees may be discouraged from sending requests to join a group on Yammer. Yammer group members are not responsible for either inviting an employee to join a group or approving an employee's request to join. That approach allows for an incredibly tight control over the number of social network groups allowed in a company and group membership. By controlling both of these parameters, the company administration efficiently manages the participants of all interactions on an Enterprise social network. Simply put, this practice allows for a tighter control over who gets to receive certain information via Yammer and who is excluded from that distribution. Also, the flow of information from a group member to Senior Leadership and the members of administration is actively managed by restricting the number of user who can generate a post or share information.

What is the objective of actively managing Yammer to limit the ability to create groups, become a group member, and create content? The main objective of this approach is to employ Yammer as a channel for managed communications.

\section{Employing Yammer as a Channel for Managed Communications}

A managed communication to and from employee groups on Yammer entails engaging employees in communications activities planned and executed by Senior Leadership. When employed in this capacity, Yammer becomes a platform on which primarily the members of the authorized organizations plan, initiate, monitor, manage, control, and terminate major communications activities. These organizations include a Change Management Organization, Enterprise Communications who are acting on behalf of Senior Leadership.

Managed communication activities systematically channel designated messages from Senior Leadership to group employees. These activities also entail soliciting and collecting information from employees in an organized fashion. Examples of managed communications activities include such events, as facilitating a virtual Town Hall with Senior Leadership, a group's 'yamming' session, or a meeting with key managers. All of these communications activities are in effect engagements. In Organizational Change Management's speak, an 'engagement' is a communication activity that entails a face-to-face interaction between groups of company employees. In other words, in a managed communication event, Yammer is used as a platform to facilitate a group meeting in a virtual environment rather than a live event in a con- 


\section{Управление в социально-экономических системах}

ference hall. More often than not, managed communication events occur in a 'vertical' fashion. The participating Yammer groups belong to distinctly different company levels. Information is channeled from Senior Leadership to company employees ('top down' communication). This could be a recording of a Senior Leader's presentation, a life presentation by Senior Leaders or company management, or a press-release approved by Senior Leadership. The flow of information is also channeled from company employees to Senior Leadership. This information flow is frequently called 'grass roots' communication. Both modes of communication are facilitated by an organization which serves as an event Moderator. Ether communication mode does not have to be purely formal. In fact, the Moderators prefer very creative, engaging, funny, and entertaining ways to communicate information. An example of a creative Yammer communication is the one called 'yamming'. 'Yamming' is an interesting phenomenon. The name came from the music culture: a jam session. Wikipedia defines a jam session as a "relatively informal musical event, process, or activity where musicians, typically instrumentalists, play improvised solos and vamp on tunes, songs and chord progressions. To 'jam' is to improvise music without extensive preparation or predefined arrangements" [9]. In an Enterprise social network environment, 'yamming' (that is, jamming in Yammer) together with other employees is akin to an event where music enthusiasts gather to enjoy playing music together. During 'yamming', Yammer group members are professionally engaged in a discussion or interaction on a topic chosen by a Moderator. Typically, the role of a Moderator is played by an Organizational Change Manager. Quite frequently, a discussion topic is chosen with intent to promote a cultural initiative and encourage and reinforce a new (desired) employee behavior. A 'yamming' session can be entertaining and include interactive activities, such as watching an instructional or motivational video, listening to a speech by an Enterprise Coach, motivational speaker, or a Senior Leader.

The seemingly entertaining way to facilitate 'yamming' in Yammer, however, does not change the controlled and managed nature of this communication event. In all these examples, Yammer is used as a venue for channeling information to a targeted employee population and from employees to Senior Leadership. In other social networks, members of a social group communicate horizontally and primarily within their social group. In a company that practices managed communications in Yammer or any other Enterprise social network, the preferred flow of information is primarily vertical. It is executed between employees and company Senior Leadership. For example, a company may choose to create a Yammer group for employees within the Supply Management core function. If a company seeks to use Yammer as a communications channel for promoting a culture change, the flow of information will primarily occur between the members of that group and Senior Leadership that leads the Global Supply Management function at the Enterprise level.

\section{Actively Governing, Monitoring, and Managing the Content \\ of Employee Communications in Yammer}

In a managed corporate social network environment, the content of all employee communications in Yammer is actively governed and regulated. This is a multi-layer process.

First, the content of any employee communication is governed by corporate communications policies. Communications created in Yammer or any other Enterprise social network are subject to the same regulations and restrictions as all employee communications in any other Enterprise communications media. Divulging company information and the practices of using inappropriate vocabulary, racial slurs, or offensive language are prohibited no matter which communication channel is used. The application of Enterprise communication governance practices is the first line of defense that is supported by content monitoring in Enterprise social networks. When hired, employees in the US sign legal agreements that govern the use of employee communications. In some companies, employees are also required to take the training to improve their awareness of the company's communications practices. Employee compliance with the current governance and regulatory practices in corporate communications is a form of active communication management practices.

Second, as Enterprise social network software, Yammer comes preset with content monitoring capabilities. Yammer is capable of tracking sensitive content. This content may include employee personal information, a particular word or expression, phrase, or another item (e.g., image). An example of a private (personal) content may be a social security number, credit card number, or an employee's personal ID number. When an employee creates a post that includes a monitored content, Yammer notifies a de- 
signated Administrator or Moderator by sending an email to a pre-determined email address. When an Administrator or Moderator receives a notification, they have an option of deleting a sensitive content off the Enterprise network. There are two data retention options. A so called Hard Delete permanently removes data off the Enterprise network. A Soft Delete makes the deleted data invisible to the Enterprise social network users (employees), but still leaves them visible for security professionals in reports. The use of these data retention practices is another example of data / information flow management practices in a corporate social network.

Consider this hypothetical example. A large manufacturing company is downsizing and is hiring an outside service provider to replace its full-time employees. Employee layoffs and the on-boarding of a service provider's employees may negatively influence employee morale. Reports will likely show negative emotions, sentiment, and attitudes in employee posts. Some of the most negative, aggressive, or inappropriate posts will be captured by Yammer before they are published. They will be deleted so that they could not be reviewed by other company employees. This deletion practice constitutes the Soft Delete approach. These posts, however, will not be Hard Deleted from company network completely. Instead, as raw data, they will become available to company communications analysts, organizational development consultants, and Organizational Change Managers. These professionals will analyze the posts to study trends in company culture, model employee behaviors, and develop communication and training strategies to improve employee morale.

Third, companies employ suppliers of Enterprise content monitoring services. A company called Social SafeGuard is one of the leading providers of social media compliance and security services. Its services include identifying and remediating inappropriate conduct and personal information that violate Enterprise communication policies. Social SafeGuard automatically detects, flags for review, purges, and / or archives words, phrases, images, attached files within employee media communications that present a risk to client companies. By monitoring Enterprise social networks Social SafeGuard allows its clients to avoid legal repercussions and the associated bad publicity that may be caused by the lack of compliance with company governance standards as well as with industry-specific regulations and policies.

Finally, the practice of actively managing the content of employee communication activities in Yammer may entail hiring a Yammer communications Monitor or delegating these responsibilities to a member of an Organizational Change Management team. This role is charged with monitoring Enterprise social network communications for content that may be upsetting, unsettling, or aggressive toward certain employee groups. For example, a company may go through a tough cultural transformation. Sometimes, those transformations entail layoffs and other unpopular personnel decisions. Yammer treats employee communications that contain negative comments about layoffs, transfers, lost benefits, employee families, increased workload, or unpopular personnel-related decisions as ordinary communications. These communications, therefore, may not be detected as policy violations by Yammer unless a human monitor detects them. A human Monitor detects, analyzes, and manually removes these messages if necessary.

Analyzing and Acting on Information Obtained from Employee Communications in Yammer

Yammer is a powerful tool for social mining on the Enterprise. This software can be used to collect and analyze data that provide an insight on employee sentiment and social dynamics of employee groups. Why is this information important for managing information flows? An organization that does not collect and analyze data about its employees' behaviors cannot efficiently manage their behaviors to promote and support innovations. In the US, organizations frequently use surveys to collect data about employee opinions on various corporate topics. A survey is an efficient data collection instrument. It does, however, have its limitations. Specifically, a survey has to account for certain amount of bias in employee responses. Under certain circumstances, employees, out of a fear of reprisal, may provide biased responses simply because the respondents say what their employer wants to hear. Also, a survey needs to be anonymous to encourage employees to provide the truthful answers. Data collected using an Enterprise social network may not have the same limitations as a survey. This data reflect employee sentiment, opinion, feelings in their communications that occur naturally. Even in its most rudimentary form, data collected on an Enterprise social network, such as Yammer, includes information on communication and discussion topics as well as on specific users and groups who express their opinions 


\section{Управление в социально-экономических системах}

(no anonymity). This data comes in the form of files, messages, topics, employee actions (e.g., liking someone's post), and pages associated with a specific user and a group or organization. Other data that can be extracted from an Enterprise social network can provide an indication of employee likes, social status in a group, and detailed user demographics. Raw social data can be further analyzed using specialized Microsoft tools (e.g., Microsoft Power BI) to visualize and model employee behaviors.

Data collection and analysis is not employed for primitive spying on company employees. An analysis may help identify informal leaders, communication trends, hot trends in employee attitudes, and gauge the overall company 'temperature'. Behavior modeling can provide information that is used to plan more efficient communications and information delivery venues. In other words, it may suggest which topics to discuss with which employee group, which company division, on which continent to discuss them, and how to ensure employee behaviors are influenced in a way that is conducive to company corporate goals.

The data can be used by various organizations within an Enterprise, including HR, Organizational Change Management, Enterprise Communications, Training and Talent Development, and Organizational Development. These organizations can use the data to facilitate more efficient communications and training activities. "Effective use of Yammer increases interactivity between employees and the management opens the possibility for feedback and increases employer engagement. Hence, it can be an asset that improves an organization's overall success" [10].

\section{Summary}

Enterprise social networks provide a powerful tool for supporting employee communications. They are frequently used to enable group communications and teamwork. The role of an Enterprise social network as a channel for promoting a corporate culture, however, is examined much less. To understand how an Enterprise social network can be used to support a company's goals and influence employee behaviors, it is important to understand how information on an Enterprise network can be managed. This article uses Yammer as an example of an Enterprise social network and examines various practices for managing the flow of information in this Enterprise social network. A few of these practices include:

- Employing a managed/controlled approach to using Yammer among company employees;

- Employing Yammer as a channel for managed communications;

- Actively governing, monitoring, and managing the content of employee communications in Yammer;

- Analyzing and acting on information obtained from employee communications in Yammer.

When applied systematically, these practices ensure an efficient flow of information from company employees to Senior Leadership. They also ensure an efficient flow of information from Senior Leadership to employees in order to provide employees with a vision and ensure support of company direction and policies. Supported by other forms of information management practices, the use of Enterprise social networks, such as Yammer, becomes an efficient instrument to promote and sustain a corporate culture change.

\section{References}

1. Borge M., Goggins S. Towards the facilitation of an online community of learners: Assessing the quality of interactions in Yammer. Proceedings of ICLS, 2014, vol. 14, p. 35.

2. PROSCI. Source: https://www.prosci.com/change-management/what-is-change-management.

3. Stul M.J. Innovation Management Methods: the US Experience. Bulletin of the Saratov State Social and Economic University, 2015, no. 3 (57), pp. 61-67. (in Russ.)

4. An interview with David Sacks, Founder and CEO of Yammer, Source: Business Insider at http://www.businessinsider.com/yammer-changing-the-way-we-communicate-at-work-2011-2.

5. Oduor M. Software Architectures for Social Influence: Analysis of Facebook, Twitter, Yammer and Foursquare, 2013, p. 40.

6. Pietarinen N. Internal Communication in a Global Technology Company: the Use of the Enterprise Social Network Tool Yammer. 2016, p. 14.

7. An interview with David Sacks, Founder and CEO of Yammer, Source: Business Insider at http://www.businessinsider.com/yammer-changing-the-way-we-communicate-at-work-2011-2. 
8. Pietarinen N. Internal Communication in a Global Technology Company: the Use of the Enterprise Social Network Tool Yammer. 2016, p. 15.

9. Wikipedia. Source: https://en.wikipedia.org/wiki/Jam session.

10. Pietarinen N. Internal Communication in a Global Technology Company: the Use of the Enterprise Social Network Tool Yammer. 2016, p. 31.

Received 1 March 2017

УДК 004.056:621.391

DOI: $10.14529 /$ ctcr170307

\title{
УПРАВЛЕНИЕ ИНФОРМАЦИОННЫМИ ПОТОКАМИ В КОРПОРАТИВНОЙ СОЦИАЛЬНОЙ СЕТИ
}

\author{
М. Стуль \\ Conducive Corporation, Чикаго, uтат Иллинойс, США
}

\begin{abstract}
В статье обсуждаются современные практики управления потоками информации в корпоративных социальных сетях. Корпоративные социальные сети достаточно широко распространены на предприятиях и в организациях. Они играют важную роль в продвижении культуры сотрудничества как внутри коллектива или рабочей группы, так и между подразделениями организаций. Корпоративные социальные сети предоставляют также и платформу для продвижения инноваций в организациях. Однако роль корпоративных социальных сетей как инструмента влияния на корпоративную культуру гораздо менее изучена. Когда речь идет о влиянии на поведение сотрудника предприятия и организации, роль корпоративной социальной сети трудно переоценить. На предприятиях и в организациях в США существуют специалисты по управлению внедрением инноваций. Они являются сотрудниками организации, которая называется Organizational Change Management Organization (OCMO). Такие организации изучают, внедряют и используют новые методы управления поведением сотрудников компании. В последние годы ОСМО активно изучают и используют возможности корпоративных социальных сетей как средства влияния на поведение сотрудников. Каковы наиболее эффективные способы управления информационными потоками в корпоративной социальной сети, чтобы добиться максимальной информативности сообщений? Каковы наиболее эффективные способы управления поведением сотрудников с помощью социальной сети, чтобы осуществить цели предприятия? Какие методы и инструменты сбора информации существуют, чтобы проанализировать и изучить поведение групп и отдельных сотрудников в корпоративных социальных сетях?

В статье исследуются современные методы и инструменты управления потоками информации на примере корпоративной социальной сети Яммер. Целевая аудитория статьи - руководители предприятий и организаций, специалисты по управлению проектами, организационной динамике и тренировке персонала.

Ключевые слова: социальные сети, медиа, Яммер, Фейсбук, Инстаграм, корпоративный, информация, США, управление внедрением инноваций.
\end{abstract}

\section{Лumepamypa}

1. Borge, M. Towards the facilitation of an online community of learners: Assessing the quality of interactions in Yammer / M. Borge, S. Goggins // Proceedings of ICLS. - 2014. - Vol. 14. - P. 35.

2. PROSCI. - https://www.prosci.com/change-management/what-is-change-management.

3. Стул, М.Я. Технологии управления нововведениями: опыт США / М.Я. Стул // Вестник Саратовского государственного соииально-экономического университета. - 2015. - № 3 (57). C. 61-67. 


\section{Управление в социально-экономических системах}

4. An interview with David Sacks, Founder and CEO of Yammer. - http://www.businessinsider.com/ yammer-changing-the-way-we-communicate-at-work-2011-2.

5. Oduor, M. Software Architectures for Social Influence: Analysis of Facebook, Twitter, Yammer and Foursquare / M. Oduor. - 2013. - P. 40.

6. Pietarinen, N. Internal Communication in a Global Technology Company: the Use of the Enterprise Social Network Tool Yammer / N. Pietarinen. - 2016. - P. 14.

7. An interview with David Sacks, Founder and CEO of Yammer. - http://www.businessinsider.com/ yammer-changing-the-way-we-communicate-at-work-2011-2.

8. Pietarinen, N. Internal Communication in a Global Technology Company: the Use of the Enterprise Social Network Tool Yammer / N. Pietarinen. - 2016. - P. 15.

9. Wikipedia. - https://en.wikipedia.org/wiki/Jam_session.

10. Pietarinen, N. Internal Communication in a Global Technology Company: the Use of the Enterprise Social Network Tool Yammer / N. Pietarinen. - 2016. - P. 31.

Стуль Михаил, PhD, специалист по обучению персонала и управлению инновациями, Conducive Corp., Чикаго, штат Иллинойс, США; mstulphd@gmail.com.

Поступила в редакцию 1 марта 2017 г.

\section{ОБРАЗЕЦ ЦИТИРОВАНИЯ}

Stul', M. Managing the Flow of Information on an Enterprise Social Network / M. Stul' // Вестник ЮУрГУ. Серия «Компьютерные технологии, управление, радиоэлектроника». - 2017. - Т. 17, № 3. C. 64-74. DOI: $10.14529 /$ ctcr170307

\section{FOR CITATION}

Stul' M. Managing the Flow of Information on an Enterprise Social Network. Bulletin of the South Ural State University. Ser. Computer Technologies, Automatic Control, Radio Electronics, 2017, vol. 17, no. 3, pp. 64-74. DOI: $10.14529 / \mathrm{ctcr} 170307$ 